Document downloaded from:

http://hdl.handle.net/10251/87715

This paper must be cited as:

Flores Pedauye, R.; Minoia, S.; Carbonell, A.; Gisel, A.; Delgado Villar, SG.; LópezCarrasco, MA.; Navarro, B.... (2015). Viroids, the simplest RNA replicons: How they manipulate their hosts for being propagated and how their hosts react for containing the infection. Virus Research. 209:136-145. doi:10.1016/j.virusres.2015.02.027

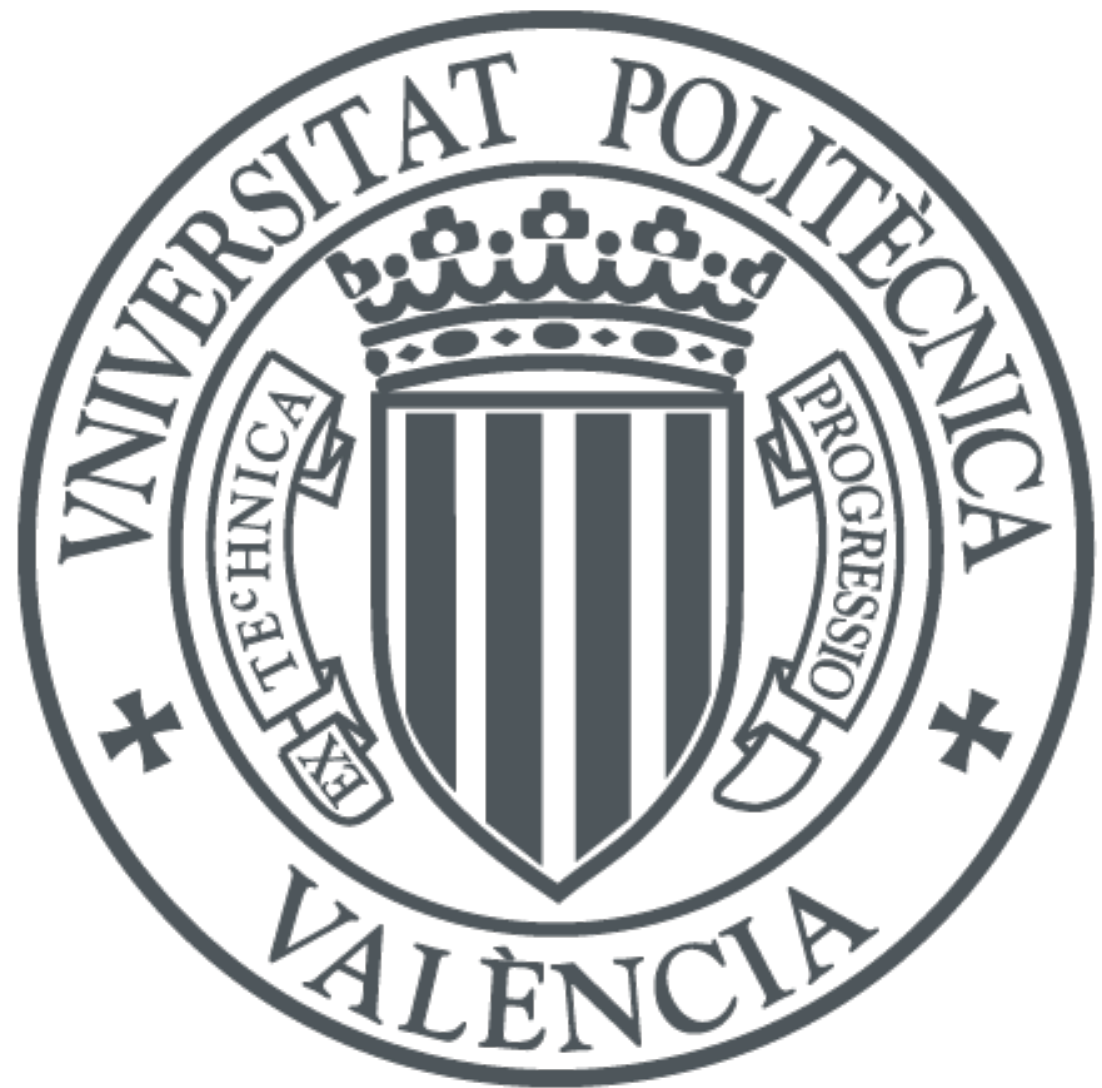

The final publication is available at

http://doi.org/10.1016/j.virusres.2015.02.027

Copyright Elsevier

Additional Information 


\title{
Viroids, the simplest RNA replicons: how they manipulate their hosts for being propagated and how their hosts react for containing the infection
}

\author{
R. Flores ${ }^{a}{ }^{*}$, S. Minoia ${ }^{a}$, A. Carbonell ${ }^{b}$, A. Gisel ${ }^{c, d}$, S. Delgado ${ }^{\text {a }}$, A. López-Carrasco a , \\ B. Navarro ${ }^{e}$, F. Di Serio ${ }^{e}$
}

${ }^{a}$ Instituto de Biología Molecular y Celular de Plantas (UPV-CSIC), Universidad Politécnica de Valencia, Valencia 46022, Spain

${ }^{\mathrm{b}}$ Donald Danforth Plant Science Center, St. Louis, Missouri, USA

${ }^{\mathrm{c}}$ Istituto di Tecnologie Biomediche, Consiglio Nazionale delle Ricerche, Bari, Italy

${ }^{\mathrm{d}}$ International Institute of Tropical A griculture, Ibadan, Nigeria

${ }^{\mathrm{e}}$ Istituto per la Protezione Sostenibile delle Piante, Consiglio Nazionale delle Ricerche, Bari, Italy

\begin{abstract}
The discovery of viroids about 45 years ago heralded a revolution in Biology: small RNAs comprising around $350 \mathrm{nt}$ were found to be able to replicate autonomously and to incite diseases in certain plants - without encoding proteins, fundamental properties discriminating these infectious agents from viruses. The initial focus on the pathological effects usually accompanying infection by viroids soon shifted to their molecular features - they are circular molecules that fold upon themselves adopting compact secondary conformations - and then to how they manipulate their hosts to be propagated. Replication of viroids - in the nucleus or chloroplasts through a rolling-circle mechanism involving polymerization, cleavage and circularization of RNA strands- dealt three surprises: i) certain RNA polymerases are redirected to accept RNA instead of their DNA templates, ii) cleavage in chloroplastic viroids is not mediated by host enzymes but by hammerhead ribozymes, and iii) circularization in nuclear viroids is catalyzed by a DNA ligase redirected to act upon RNA substrates. These enzymes (and ribozymes) are most probably assisted by host proteins, including transcription factors and RNA chaperones. Movement of viroids, first intracellularly and then to adjacent cells and distal plant parts, has turned out to be a tightly regulated process in which specific
\end{abstract}


RNA structural motifs play a crucial role. More recently, the advent of RNA silencing has brought new views on how viroids may cause disease and on how their hosts react to contain the infection; additionally, viroid infection may be restricted by other mechanisms. Representing the lowest step on the biological size scale, viroids have also attracted considerable interest to get a tentative picture of the essential characteristics of the primitive replicons that populated the postulated RNA world.

\section{KEYWORDS}

Keyw ords: Catalytic RNAs, Non-protein-coding RNAs, Ribozymes, RNA silencing 


\section{Introduction}

Within the frame of the International Symposium sponsored by the Fundación Ramón Areces "Cell response to viral infection: search for new therapeutic targets" giving rise to this special issue of Virus Research - the present review is uncommon in two aspects: it deals neither with viruses nor with animal systems, but with viroids that infect plants. Despite this apparent dissonance, two reasons make us feel that it may be of interest for readers. Firstly, discoveries in plant systems have preceded and paved the way for subsequent research with great impact on animals and humans. Cytology, genetics and, particularly, virology, are three excellent but not exclusive examples. The agent of tobacco mosaic disease, tobacco mosaic virus (TMV), was the first virus to be discovered (Beijerinck, 1898), opening the door to a subcellular world populated by many other viruses infecting and frequently inciting numerous diseases in all type of organisms. Moreover, the discovery of plant viroids, and specially of potato spindle tuber viroid (PSTVd) (Diener, 1971, 1972), opened the door to a subviral world and served as a reference for ensuing work that led to the identification and characterization of a viroid-like pathogen, human hepatitis delta virus (HDV) (Rizzetto et al., 1980; for a review see Flores et al., 2012a). And secondly, as we will see, viroids parasitize their hosts —and the latter react to the infection - in a unique manner that illustrates how versatile the interactions between cells and their invaders can be.

\section{Viroids: a brief account of fundamental concepts}

Despite been discovered about 45 year ago (see for reviews Diener 2003; Ding, 2009; Di Serio et al., 2014; Flores et al., 2005; Gómez and Pallás, 2013; Kovalskaya and Hammond, 2014; Palukaitis, 2014; Tsagris et al., 2008), viroids still require some introduction for non-plant virologists. Even if their name evokes some kind of degenerated viruses, viroids bear no structural, functional or evolutionary relationship with viruses. We will first summarize here the singular properties of viroids, and move then to describe the interactions with their hosts.

In a certain way viroids represent the border of life, since they are the smallest biological entities endowed with autonomous replication in an appropriate environment (a host cell) (Fig. 1), an aspect that has attracted much interest in the 
frame of the origin and evolution of life on Earth (Diener, 1989, 1996; Flores et al., 2014). From a physical standpoint, they are minuscule (about 250-400 nt) singlestranded circular RNAs, this size being 4-7 fold smaller than that of the smallest genome of an animal virus (HDV RNA), and approximately 20 -fold smaller than that of the genomic TMV RNA. Moreover, as a consequence of their high selfcomplementary sequences, viroid RNAs fold upon themselves adopting compact secondary structures (Fig. 1; see also Fig. 1 in Flores et al., 2014) that most likely afford protection against endoribonucleases, the majority of which act upon singlestranded RNAs (Gross et al., 1978; Flores et al., 2012b). Adoption of these compact secondary structures is also facilitated by circularity, which additionally hampers degradation catalyzed by exoribonucleases. Circularity would also impede translation of potential viroid-encoded proteins, at least by the conventional ribosome scanning mechanism demanding a 5' terminus. Indeed, several lines of evidence strongly support the view that viroids are non-protein-coding RNAs, including the absence of open reading frames of a certain length conserved among closely-related viroids (Gross et al., 1978; Haseloff and Symons, 1981), and the lack of specific protein products both in different in vitro and in vivo translation systems from bacterial and eukaryotic origin primed with viroid RNAs - and in viroidinfected plants (Conejero et al., 1979; Davies et al., 1974; Hall et al., 1974; Semancik et al., 1977; for reviews see Flores et al., 2000; Diener, 2001). Therefore, as opposed to viruses, which without exception code for proteins that mediate their replication, trafficking and overcoming of host defensive barriers, viroids rely essentially on host proteins and on some of their own RNA features to achieve these aims. The RNA of a typical positive-stranded virus, like TMV, can be envisaged as a parasite of the cell translation machinery: once released from the viral capsid, this RNA associates with ribosomes to express the proteins it encodes. In contrast, the RNA of a viroid can be regarded as a transcriptional parasite because, after entering the host cell, it must get access to specific compartments and sequester enzymes (including RNA polymerases) for replication.

The thermodynamically most stable structure - i.e., with the lowest free energy content - predicted for the majority of the approximately 30 known viroids is a rod like conformation with a central conserved region (CCR) (McInnes and Symons, 
1991) formed by two nucleotide stretches each located in the upper and lower strands (for a review see Flores et al., 2012b) (see Fig. 1 in Flores et al., 2014). There is biochemical/ biophysical evidence supporting that this in silico conformation, or minor variations thereof, exist also in vitro (Giguère et al., 2014a; Gross et al., 1978; Riesner et al., 1979; Sänger et al., 1976; for a review see Flores et al., 2012b), and in vivo, because viable variants resulting from deletions/ duplications preserve the rodlike conformation (Haseloff et al., 1982; Semancik et al., 1994; Wassenegger et al., 1994a). Viroids with these structural features are assigned to the family Pospiviroidae (type member PSTVd), and have a functional correlate: they replicate in the nucleus of infected cells, wherein several RNA polymerases and processing enzymes reside (see below). On the other hand, four viroids do not meet these two structure/ sequence criteria and usually adopt branched conformations, supported by in silico, in vitro and in vivo data (Ambrós et al., 1998; Delan-Forino et al., 2014; De la Peña et al., 1999; Giguère et al., 2014b; Hiu-Bon-Hoa et al., 2014; Navarro and Flores, 1997; for a review see Flores et al., 2012b), without a CCR. In stead, the strand s of both polarities contain short stretches of conserved nucleotides that form the central core of the so-called hammerhead ribozymes (see Fig. 1 in Flores et al., 2014), which play a key role in replication (Daròs et al., 1994; Hutchins et al., 1986). These four viroids endowed with catalytic activity are grouped within the family Avsunviroidae (type member avocado sunblotch viroid, ASBVd) (Symons, 1981), and have an alternative functional correlate: they replicate in plastids (mostly chloroplasts), which like nuclei, contain several RNA polymerases and processing enzymes (see below).

\section{How viroids coerce their host plants for being replicated and translocated}

Replication of viroids differs in fundamental aspects from that of positivestranded RNA viruses. Three-dimensional electron microscope tomographic imaging has revealed that the latter replicate in membranous vesicles that are associated with the periphery of different organelles and connected with the cytoplasm through a narrow channel. These organelle-like RNA replication factories are virus-induced and contain replicative intermediates and viral non-structural proteins (den Boon and Ahlquist, 2010). In contrast, viroid s replicate inside preformed organelles, nuclei 
or plastids, with no data showing that these infectious RNAs induce the formation of specific bodies, although replication efficiency and protection from host defenses most likely impose some sort of compartmentalization.

The available evidence, essentially obtained with PSTVd and closely-related viroids, supports that their replication (and by extension that of the other members of the family Pospiviroidae), occurs in the nucleus through an asymmetric rolling-circle mechanism (Branch et al., 1988; Daròs and Flores, 2004; Feld stein et al., 1998) (see Fig. 3 in Flores et al., 2014). Briefly, the infecting circular RNA (of plus polarity by convention) is repetitively transcribed by an RNA polymerase into oligomeric (-) strands, which in turn serve as templates for a second transcription round - most likely mediated by the same RNA polymerase- resulting in oligomeric (+) RNAs. Their subsequent cleavage into unit-length strands by an RNase, and circularization by an RNA ligase, produces progeny identical (excluding mutations introduced accidentally) to that initiating the replication cycle. Experimental support for the templates operating in this model comes from the identification of the PSTVd oligomeric (+) and (-) strands in nuclei isolated from infected cells (Spiesmacher et al., 1983). Moreover, PSTVd (+) strands accumulate in the nucleolus and nucleoplasm, in contrast with the complementary strands that have been detected only in the nucleoplasm (Qi and Ding, 2003), an observation suggesting that RNA initiation and elongation occurs in this latter compartment while processing of $(+)$ strands would take place in the nucleolus. Regarding the enzymes catalyzing the three replicative steps, a detailed account of the first two has been provided before (Flores et al., 2009). Here we will just recapitulate that the RNA polymerase mediating elongation of viroid strands is not one of the multiple RNA-directed RNA polymerases (RDRs) described in plants (Schieble et al., 1998; Wassenegger and Krczal, 2006) but, surprisingly, the nuclear DNA-dependent RNA polymerase II (pol II) redirected to transcribe RNA templates (Flores and Semancik, 1982; Mühlbach and Sänger, 1979; Schindler and Mühlbach, 1992; Warrilow and Symons, 1999). Because the transcription factor IIIA (TFIIIA) from A. thaliana binds PSTVd (+) RNA in vitro with the same affinity as its physiological ligand 5S rRNA, and because TFIIIA also binds to the DNA gene coding for the latter, this dual capacity could enable TFIIIA to act as a bridge between the viroid RNA template and pol II (Eiras et 
al., 2011). Recent analyses have provided direct support for this view, since PSTVd interacts in vitro and in vivo with TFIIIA from Nicotiana benthamiana, and its downregulation and overexpression results in reduced and increased accumulation of PSTVd, respectively (Wang et al., 2014). Related to this point is the observation that tomato pol II interacts in a nuclear extract with the left terminal domain of the PSTVd (+) RNA (Bojić et al., 2012). Whether this interaction is direct or mediated by a transcription factor, like TFIIIA, remains to be addressed. On the other hand, the enzyme catalyzing cleavage of oligomeric $(+)$ strands most likely belongs to class III RNases, which act preferentially upon highly-structured nuclear transcripts (in the case of viroids a double-stranded segment formed by the upper CCR strand of two units of the oligomeric replicative intermediates) (Gas et al., 2007); however, the specific member(s) of the class involved is yet unknown. The characterization of the enzyme mediating the final circularization step has brought another surprise: it is not a conventional RNA ligase, as intially presumed, but the nuclear DNA ligase 1 redirected to ligate RNA substrates (Nohales et al., 2012a), once again highlighting the ability of viroids to manipulate the transcription and processing machinery of their hosts. In this instance the substrate specificity of a DNA ligase, and in the previous one the template specificity of an RNA polymerase.

Members of the family Avsunviroidae replicate in plastids according to a symmetric rolling-circle mechanism mostly elucidated using the ASBVd-avocado system (Daròs et al., 1994; Hutchins et al., 1985) (see Fig. 3 in Flores et al., 2014). The discriminating feature is that cleavage and ligation occurs here in the oligomeric strands of both polarities, and not only in those of (+) polarity as in PSTVd and related viroids, thus resulting in monomeric circular (-) strands that are the template for a second rollingcircle symmetric with respect to the first one. Strikingly, cleavage is not mediated by a host RNase, but by hammerhead ribozymes embedded in the oligomeric strands of both polarities (Hutchins et al., 1986; Prody et al., 1986). This singular feature has deep implications, prominent among which is the possibility of a very primitive evolutionary origin for viroids in a primordial RNA world that emerged on Earth more than 3=billion years ago (Diener, 1989; Flores et al., 2014). Recent data suggest that phosphorylated biomolecules, like RNA, may have first formed from the reaction of reduced $\mathrm{P}$ species with the prebiotic organic milieu on the early Earth 
(Pasek et al., 2013). Experimental evidence for the symmetric rolling-circle mechanism, and for the subcellular site wherein it operates, comes from the identification of RNA complexes formed by multimeric and monomeric circular and linear ASBVd RNAs of both polarities in chloroplasts from infected tissue (Navarro et al., 1999). Elongation of viroid strands is catalyzed by a nuclear-encoded chloroplastic RNA polymerase (NEP) redirected to transcribe RNA templates (Navarro et al., 2000; Rodio et al., 2007). How members of both families have evolved the same strategy remains an intriguing conundrum considering that pol II and NEP differ significantly in their structural complexity: the former is a multisubunit complex, the latter is a single-subunit enzyme. The third replication step, circularization, is catalyzed by an isoform of the tRNA ligase, which like NEP, is encoded in the nucleus and then translocated into the chloroplast via a signal peptide (Nohales et al., 2012b). The possibility that circularization might proceed via selfligation without the involvement of enzymes (Côté et al., 2001), appears less likely (Flores et al., 2009). Finally, ASBVd has been reported to replicate in cells of Saccharomyces cerevisiae following expression of multimeric ASBVd (+) or (-) transcripts launched from a yeast vector (Delan-Forino et al., 2011). However, since yeasts lack chloroplasts, it is difficult to link these results with those obtained in the natural context (ASBVd-avocado).

Before initiating replication, viroids must move intracellularly to the organelle wherein this process takes place, with the resulting progeny then trafficking intercellularly through plasmodesmata and systemically through the phloem. Regulation of these movements has been finely dissected in studies mostly focusing on PSTVd in N. benthamiana and tomato. The import of this viroid into the nucleus is driven by a sequence or structural motif mapping at the upper strand of the CCR (Abraitiene et al., 2008; Zhao et al., 2001;), and is cytoskeleton-independent, uncoupled to the Ran GTPase cycle, and facilitated by a specific and saturable receptor (Woo et al., 1999). Other motifs, particularly specific loops/ bulges in the rod-like secondary structure, mediate entry of PSTVd from non-vascular into phloem tissue (Zhong et al., 2007), trafficking from palisade to spongy mesophyll (Takeda et al., 2011), and trafficking from the bundle sheath to mesophyll (Qi et al., 2004). A genome-wide mutational analysis has assigned to all PSTVd loops/ bulges roles in 
replication in single cells or in systemic movement (Zhong et al., 2008). Independent studies have associated systemic movement with a small purine/ pyrimidine motif in the right terminal domain of the rod-like secondary structure, conserved in all members of the genus Pospiviroid, which specifically interacts with a bromodomaincontaining protein from tomato that may facilitate transport into the nucleus (Gozmanova et al., 2003; Martínez de Alba et al., 2003). Other candidate proteins for mediating this function have also been proposed (Eiras et al., 2011). Within the phloem, the phloem protein 2 (from cucumber) —which binds in vitro to hop stunt viroid (HSVd) and PSTVd RNAs - has been suggested to mediate their longdistance trafficking (Gómez and Pallás 2001; Owens et al., 2001). More recently, the involvement of another protein from tobacco ( $\mathrm{Nt}-4 / 1)$, with which PSTVd interacts, has been invoked as well (Solovyev et al., 2013), although its role in viroid movement is not yet clear. The studies addressing this issue in the family Avsunviroidae are considerably more limited. According to recent data, the monomeric linear (+) RNA of eggplant latent viroid $(E L V d)$ has ability for trafficking from the cytoplasm into the nucleus and then from this organelle into chloroplasts, where it is replicated. An RNA sequence or structural motif mapping at the left terminal domain of the ELVd RNA seems to mediate this trafficking (Gómez and Pallás, 2012). Viroid RNA entry in the chloroplast might be escorted by certain nuclear-encoded proteins with a signal peptide for being translocated into the chloroplast, particularly considering that these proteins specifically bind the ASBVd (+) RNA in vivo and facilitate hammerhead-mediated self-cleavage (i.e. they are RNA chaperones) (Daròs and Flores, 2002).

\section{How host plants react for containing viroid infection: RNA silencing}

Viroids are the causal agents of a number of diseases in cultivated herbaceous and ligneous plants, dicotyled ons and monocotyledons. Viroids are mainly transmitted by vegetative propagation of infected material and incite in their hosts symptoms that typically include leaf chlorosis, internode shortening, bark cracking, flower discoloration, fruit skin deformation and tuber malformation. Some viroids, however, do not induce any discernible symptoms (Flores et al., 2005). Even before direct evidence became available, it was anticipated that — like viruses - viroids 
should elicit some sort of host defensive response to restrain or attenuate the deleterious effects they usually trigger. A sort of hypersensitive reaction, which in the so-called local-lesion hosts restricts infection by certain RNA viruses (e.g. TMV) to a few cells surrounding that infected initially (Scholthof, 2014), was also reported in Scopolia sinensis infected by PSTVd (Singh, 1971). However, the narrow range of experimental conditions allowing observation of this effect precluded subsequent in depth dissection.

Discovery of post-transcriptional gene silencing (PTGS) in plants (for a review see Eamens et al., 2008), and later in animals and fungi, illuminated this issue because PTGS presumably first emerged as a defensive mechanism against invading nucleic acids. This mechanism later diversified and assumed regulatory functions in development. The molecular PTGS triggers are double-stranded RNAs (dsRNAs) and single-stranded RNAs (ssRNAs) with a compact secondary structure that are recognized and processed by specific members of class III RNases (termed Dicer-like, DCL, in plants) (Qi et al., 2005) into small RNAs (sRNAs), mainly microRNAs (miRNAs, of 21-22 nt) and small interfering RNAs (siRNAs, of 21, 22 and $24 \mathrm{nt}$ ) (Axtell, 2013). Some of these (primary) siRNAs activate an amplification circuit catalyzed by a specific host RDR (Wassenegger and Krczal, 2006) and DCL, eventually generating mobile secondary siRNAs that ultimately induce systemic (non-cell autonomous) RNA silencing (Dunoyer et al., 2010; Molnar et al., 2010). Moreover, one strand of the DCL-generated sRNA duplexes binds specifically to one Argonaute (AGO) protein, forming the core of the RNA silencing complex (RISC), and direct it to functionally inactivate the complementary RNA (by cleavage or translation arrest) or DNA (by methylation resulting in transcriptional gene silencing, TGS) (Mallory and Vaucheret, 2010). Therefore, invading RNA viruses, are contained by two barriers, the key components of which are the structure-specific DCLs (Molnar et al., 2005) and the sequence-specific AGOs (Omarov et al., 2007; Pantaleo et al., 2007).

Do these barriers also contain infection by viroid RNAs? Strong evidence supports that this is the case for the first one mediated by DCLs. Northern-blot hybridization and ensuing characterization, by conventional and high-throughput sequencing, have revealed the accumulation in tissues infected by representatives of both families 
of viroid-derived sRNAs (vd-sRNAs) structurally resembling the typical DCL products of endogenous and viral origin (for reviews see Hammann and Steger, 2012; Navarro et al., 2012a; Sano et al., 2010). Because the most abundant vd-sRNAs derived from PSTVd and peach latent mosaic viroid (PLMVd) (Hernández and Flores, 1992), a member of the family Avsunviroidae, do not map at the highlystructured regions predicted in their genomic (+) and (-) RNAs, it is unlikely that the latter could be the major DCL substrates. Instead, the dsRNAs produced by one or more RDRs copying the genomic viroid RNAs —which lacking cap structure and poly-A tail look like aberrant RNAs- appear better candidates (for a review see Navarro et al., 2012a). The finding of similar amounts of (+) and (-) vd-sRNAs in tissues infected by PSTVd (Dierman et al., 2010; Di Serio et al., 2010) and PLMVd (Bolduc et al., 2010; Di Serio et al., 2009) is also consistent with this view, particularly considering that the PSTVd genomic (+) strand accumulates at a significantly higher level than its complementary counterpart (Branch et al., 1988). The dsRNAs resulting from replication could also serve as additional substrates in the case of PSTVd, but not in that of PLMVd because DCLs have been documented in nuclei, but not plastids so far. Somewhat in contrast with all the previous data, a recent study has reported that DCL4 - but not DCL2 - may have a positive effect on PSTVd accumulation in $N$. benthamiana (Dadami et al., 2013); these results, however, are difficult to interpret at present.

Although dicing of the highly-structured genomic viroid ssRNA, and of its dsRNA replication intermediates, might by itself contain viroid infection below a threshold value, a "dicing-only" mechanism appears unlikely. Indeed, distinct arguments support the additional participation of one or more AGOs. First, early work showed that PSTVd replication directs de novo methylation of cDNA sequences transgenically inserted in the tobacco genome in an RNA-directed sequence-specific manner (Wassenegger et al., 1994b), providing the first example of TGS (now know $n$ to be mediated by certain DCL-dependent siRNAs and AGOs). Second, both the expression of GFP-PSTVd fusion transgenes and the viroid titer in plants infected by representative members of the two families appear to be attenuated by vd-sRNAs in a sequence-specific manner (Carbonell et al., 2008; Itaya et al., 2007; Kasai et al., 2013; Schwind et al., 2009; Vogt et al., 2004). Third, knock-d own of RDR6 increases the titer 
of PSTVd in early-infected $N$. benthamiana and additionally facilitates its entry into floral and vegetative meristems (Di Serio et al., 2010), thus suggesting the involvement of secondary vd-sRNAs in these processes. Fourth, the titer of a viroid is also enhanced by a virus coinfecting a common citrus host via the expression of viral-encoded RNA silencing suppressors (RSSs) (Serra et al., 2014), with one of them possibly affecting the function of one or more AGOs (Ruiz-Ruiz et al., 2013). And fifth, intriguing data support that certain symptoms induced by a plastid-replicating viroid (PLMVd) result from the AGO-mediated cleavage of a specific host mRNA (Navarro et al., 2012b), providing direct evidence for an early model (Papaefthimiou et al., 2001; Wang et al., 2004). Because this last argument is relevant in other contexts, we will elaborate on it in the next section.

\section{RNA silencing and viroid-host interactions: a two-w ay street}

As indicated above, host plants use RNA silencing to restrict viroid infection. Conversely, viroids most likely also use RNA silencing to modulate host genome expression for their own benefit (Navarro et al., 2012a). This idea has been put forward previously for virus-host interactions (Llave, 2010; Moissiard and Voinnet, 2006), and has received further support from subsequent data obtained with the yellow satellite RNA (Y-sat) of cucumber mosaic virus (CMV) (satellite RNAs depend on specific helper viruses, such as CMV, for their replication, encapsidation and transmission) (Shimura et al., 2011; Smith et al., 2011). More specifically, like some PLMVd variants, the small (369 nt) non-protein-coding Y-sat linear RNA exerts its pathogenic effects via PTGS. Since this proposal has been recently reviewed (Navarro et al., 2012a; Wang et al., 2012), here we will simply summarize its most salient features and add some supporting considerations.

The primary cause of the yellow phenotype incited in tobacco by Y-sat infection is a 22-nt satellite siRNA of (+) polarity - derived from the 24-nt fragment of the genomic Y-sat containing the pathogenic determinant - which is complementary (including four G-U pairs) to a 22-nt sequence of the mRNA of the chlorophyll biosynthetic gene CHLI and targets it for cleavage at the predicted position (in the middle of the 22-nt complementary sequence) (Shimura et al., 2011; Smith et al., 2011). The CHLI mRNA is also downregulated in transgenic tobacco lines expressing 
Y-sat inverted repeats, and site-directed mutagenesis to make the infecting Y-sat sequence complementary to the corresponding 22-nt fragment of the A. thaliana and tomato CHLI mRNAs results also in the leaf yellowing (Shimura et al., 2011).

On the other hand, the primary lesion of peach calico (PC), an extreme albinism induced by certain variants of PLMVd having a specific 12-14 nt insertion with which this symptomatology is strictly associated (Fig. 2), is most likely cau sed by two $21-\mathrm{nt}$ $\mathrm{vd}$-sRNAs of (-) polarity (PC-sRNA8a and b) that differ in one position and contain the pathogenic determinant (Malfitano et al., 2003; Rodio et al., 2006). The two viroid siRNAs are complementary —excluding one U-U mismatch, and in PC-sRNA8b additionally one G-U pair, both outside positions 2 to 13 that are critical for plant miRNA-directed target repression - to a 21-nt sequence of the peach mRNA coding for the chloroplastic heat-shock protein 90 (cHSP90) and target it for cleavage at the expected site (between positions 10 and 11 of the siRNAs) (Fig. 3). These results thus offer a plausible mechanism of pathogenesis considering that cHSP90 is a chaperone involved in chloroplast biogenesis and that a single-amino acid mutation in cHSP90 induces a yellow phenotype in A. thaliana (Navarro et al., 2012b). The features of PCsRNA8a and b supporting that they participate in PTGS-mediated cleavage of cHSP90 mRNA are summarized in Fig. 4. The two sRNAs fulfill the criteria for being functional sRNAs (Iwakawa and Tomari, 2013; Liu et al., 2014; Mallory et al., 2004) and having a 5'-terminal $\mathrm{U}$-in fact, their 5' termini are formed by four consecutive Us - they are most likely loaded by AGO1 (Mi et al., 2008; Montgomery et al., 2008; Taked a et al., 2008), a major player in PTGS through cleavage or translation arrest of its endogenous and foreign RNA targets (Baumberger and Baulcombe, 2005; Morel et al., 2002). These criteria are also met by the 22-nt sRNA derived from the Y-sat, which interestingly also has a 5' terminus with four consecutive Us. It is also worth noting that the target sites of the 21-nt PC-sRNA8a and b, and of the 22-nt sRNA from the Y-sat, are located in the open reading frame portion of the mRNAs, following the general trend observed for plant sRNAs (Addo-Quaye et al., 2008; Allen et al., 2005) but not for animal sRNAs, wherein the target sites are commonly found in the 3'-untranslated region (Bartel, 2009).

The possibility that vd-sRNAs derived from other PLMVd regions, apart from that containing the PC determinant, could down-regulate additional peach genes and 
incite alternative symptoms - like peach mosaic and distinct chlorotic phenotypesremains an open issue. In support of a previous hypothesis suggesting that at least a part of the corresponding molecular determinants might also reside in the same loop A wherein the PC-associated insertion maps (Malfitano et al., 2003), a unique nucleotide change in such a loop has been proposed to cause yellowing (U338) and chlorotic-edge (C338) symptoms (Wang et al., 2013). However, there is no indication so far of the peach mRNAs potentially targeted by vd-sRNAs with this single polymorphism. Moving to the family Pospiviroidae, a similar PTGS mechanism has been proposed for the phenotypes induced by the transgenic expression in some Nicotiana species of artificial miRNAs (amiRNAs) derived from the virulencemodulating region of PSTVd (Eamens et al., 2014), although the evidence is circumstantial and the most relevant amiRNA does not fulfill all the criteria listed above for PC-sRNA8a and b (Fig. 4). Also in the context of the family Pospiviroidae, infection by HSVd of $N$. benthamiana has been associated with changes in DNA methylation of host ribosomal RNA genes (Martínez at al., 2014), but whether those changes result from direct or indirect effects, and whether they play a role in pathogenesis, is not known.

In brief, direct experimental support for the idea that some RNA replicons incite symptoms via their siRNAs generated by RNA silencing is restricted so far to one CMV satellite RNA (sat-Y) and to certain variants of PLMVd inducing PC, with the evidence being particularly strong in the first case. Phenotypes induced by other satellite RNAs and by other viroids, specially of the family Pospiviroidae - wherein the down regulation of tomato pre-miRNAs or mRNAs targeted potentially by PSTVd-sRNAs has been found associated with symptoms (Dierman et al., 2010; Wang et al., 2011) — may or may not be ultimately mediated by a similar mechanism. For instance, alternatively to RNA silencing, activation of a plant enzyme homologous to the mammalian p68 protein kinase has been suggested to represent the triggering event in PSTVd pathogenesis (Diener et al., 1993; Hammond and Zhao, 2000; Kovalskaya and Hammond, 2014). Furthermore, the lack of direct evidence for the involvement of virus-derived sRNAs (vsRNAs) in symptom induction is intriguing because - being the genomic size of most RNA viru ses, like CMV, at least one order of magnitude larger than that of sat-Y and PLMVd - the wider spectrum 
of vsRNAs could in principle in activate a wider array of host mRNAs (Navarro et al., 2012a). On the other hand, the finding that host mRNAs appear targeted by AGOs loaded with sRNAs derived from some viroids and satellite RNAs, supports indirectly that these subviral replicons, like RNA viruses, are also RISC-targeted (see below).

At the beginning of this section we pointed out that host plants use RNA silencing to restrict viroid infection and that, in turn, viroids most likely strike back and use RNA silencing to tune the host genome expression to their own benefit (Navarro et al., 2012b). What is the evidence supporting this view? In peach seedlings infected by PLMVd variants inducing PC, the accumulation of PLMVd (+) and (-) strands is higher in the albino leaf sectors than in the surrounding green sectors (Fig. 5), in accordance with previous results with the ASBVd/avocado system, wherein the viroid also accumulates to higher level in "bleached" foliar areas (Semancik and Szychowski, 1994). Moreover, the PC-expressing sectors show altered plastids with irregular shape and size, and with rudimentary thylakoids resembling proplastids (Rodio et al., 2007). Altogether these observations suggest that by reducing the level of the cHSP90 mediating chloroplast biogenesis, PLMVd generates a more favorable environment for its replication (Navarro et al., 2012a). Therefore, rather than a fortuitous consequence of viroid infection, symptoms (at least some) may be regarded as an effect induced to enhance viroid survival. Considering the high number of peach mRNAs predicted to be targeted by PLMVd-sRNAs (Navarro et al., 2012a), such a scenario appears feasible.

However, despite all these data, an important link was missing: the lack of direct evidence to uphold the hypothesis that AGOs indeed recruit vd-sRNAs. This evidence has been provided recently (Minoia et al., 2014). In leaves of PSTVdinfected $N$. benthamiana, the endogenous AGO1 and distinct epitope-tagged AGOs from A. thaliana that were overexpressed -AGO1, AGO2, AGO3, AGO4, AGO5 and AGO9, but not AGO6, AGO7 and AGO10 - associate with vd-sRNAs displaying the same properties (5'-terminal nucleotide and size) reported previously for endogenous and viral sRNAs (Mi et al., 2008; Montgomery et al., 2008; Taked a et al., 2008). The AGO-loaded vd-sRNAs adopt specific distributions along the viroid genome. Moreover, overexpression of AGO1, AGO2, AGO4 and AGO5 attenuate 
viroid accumulation, bolstering the role of RISC in antiviroid defense. This view is consistent with recent results in vitro showing that RISC promotes cleavage of viral RNAs with a packed secondary structure — resembling that of viroids - by targeting bulged regions within the structure (Schuck et al., 2013). Pertinent to this context is that, in contrast with the situation observed in $N$. benthamiana infected by RNA viruses (Várallyay et al., 2010), PSTVd infection of the same host affects neither the accumulation of the endogenous AGO1 nor that of the miR168 regulating AGO1 mRNA expression (Mallory and Vaucheret, 2009). However, recent data support that infection by citrus exocortis viroid, a close relative of PSTVd, induces the accumulation of other enzymes that mediate RNA silencing in tomato (Campos et al., 2014), a finding that deserves further analysis to investigate whether this accumulation is a direct or indirect effect, and the nature of the operating mechanism.

\section{How host plants contain viroid infection: alternative mechanisms}

Viroid accumulation in infected tissues results from the balance between replication (transcription and processing) and decay. However, while remarkable advancement has been achieved in identifying the templates and enzymes involved in replication (see the third section of this review), progress on how viroid RNAs decay has been much more limited. As described in the two previous sections, the barriers raised by RNA silencing (mediated by DCLs and AGOs), target viroid RNAs for degradation. It is nevertheless likely that other degradation pathways may also operate on viroid RNAs, but the data available are basically limited to: i) the increase of certain nucleolytic activities in PSTVd-infected tomato related apparently to symptom expression rather than to viroid RNA degradation (Matousek et al., 2007), and ii) the detection by Northern-blot hybridization in immature pollen from hop plants infected by hop latent viroid (family Pospiviroidae), of discrete viroid RNA fragments (230 to $100 \mathrm{nt}$ ) that were associated with developmentally activated nucleases (Matousek et al., 2008).

Studies on decay of viroid (and many other) RNAs have been possibly neglected by the implicit assumption that degradative routes generate a mixture of heterogeneous products difficult to analyze individually. However, recent results 
show that this may not be the case and that, by selecting appropriate viroid-host combinations, the fine dissection of decay pathways may become experimentally feasible. More specifically, studies on PSTVd infection in different solanaceous hosts by Northern-blot hybridizations with specific probes have revealed in eggplant, and to a lesser extent in $N$. benthamiana and tomato, a set of PSTVd (+) subgenomic RNAs (sgRNAs) accompanying the monomeric circular and linear forms. Further characterization by primer extension and 5'- and 3'-RACE did not detect a common 5 ' terminus in the $(+)$ sgRNAs - excluding that they could be aborted products of transcription initiated at one specific site- and showed that they have 5'-OH and 3'P termini. The same approaches also unveiled PSTVd (-) sgRNAs with features similar to their (+) counterparts (Minoia et al., 2015). Where do these sgRNAs come from? As indicated in the third section, two major PSTVd pools appear to exist: one in the nucleoplasm, where elongation of viroid s strand s of both polarities occu rs, and the other in the nucleolus, where only (+) polarity strands are processed (Qi and Ding, 2003). The finding of PSTVd sgRNAs of both polarities suggest that they are produced in the nucleoplasm during elongation of viroid strands. Moreover, since most RNases generating 5'-OH and 3'-P termini have a preference for singlestranded regions -and the 5' termini of the PSTVd (+) sgRNAs do not preferentially map at loops in the rod-like secondary structure of the monomeric circular formthis latter RNA does not seem to be a plausible precursor. On the other hand, the concurrent detection of PSTVd (-) sgRNAs suggests that they are products of the endonucleolytic cleavage of nascent (-) strands, because the strands of this polarity form part of replicative intermediates and should be less vulnerable to RNases with preference for ssRNAs (Minoia et al., 2015). These results provide a deeper insight into a novel route of viroid decay in vivo, possibly proceeding during replication, and suggest that synthesis and decay of PSTVd strands might be connected as observed previously in mRNA (Haimovich et al., 2013).

\section{Conclusions and pending issues}

Most of the viroids inducing diseases in plants of economic interest have been probably discovered by conventional techniques based on the detection of the characteristic small circular RNAs by denaturing PAGE, or on the RT-PCR 
amplification with genus-specific degenerate primers. Latent viroids, however, may go easily unnoticed, as illustrated by the recent identification and characterization of a new one infecting dahlia, an important ornamental (Verhoeven et al., 2013). This situation is rapidly changing with the advent of deep sequencing approaches combined with homology-independent bioinformatic approaches, which have resulted in the discovery of a persimmon viroid (Ito et al., 2013) and three new viroid-like RNAs from grapevine and apple (Wu et al., 2012; Zhang et al., 2014). In a structural context, the old paradigm that assumed the rod-like second ary structure as a universal feature of viroids is now restricted to the family Pospiviroidae, because most members of the family Avsunviroidae adopt a clearly branched conformation occasionally stabilized by tertiary interactions. Regarding replication, we have a reasonable picture of the major templates, enzymes and ribozymes involved, with the other side of the coin (decay) still being explored. Main issues in viroid movement remain also to be addressed, particularly within the family Avsunviroidae. A major leap forward has been achieved in pathogenesis with the discovery that this process is most likely mediated, at least in certain PLMVd variants, by PTGS through DCL-generated vd-sRNAs containing the pathogenicity determinant that load and guide specific AGOs — presumably AGO1 - for cleaving a specific host mRNA. Finally, how viroids evolve in time and space during host colonization, including the existence of bottlenecks, is mostly unknown. This question is intriguing, particularly considering that the mutation rate estimated for one viroid (CChMVd) is the highest reported for any biological entity (Gago et al., 2009).

\section{Acknowledgements}

Research in R.F. laboratory is currently funded by grants BFU2011-28443 and ACOMP/ 2014/ A/ 103 from the Ministerio de Economía y Competitividad (MINECO) and Generalidad Valenciana, respectively. S.M., S.D. and A.L.-C. have been supported by fellowships or contracts from MINECO. Research in B.N. and F.D.S. laboratory has been funded by a dedicated grant of the Ministero dell'Economia e Finanze Italiano to the CNR (CISIA, Legge n. 191/ 2009). 


\section{References}

Abraitiene, A., Zhao, Y., Hammond, R., 2008. Nuclear targeting by fragmentation of the potato spindle tuber viroid genome. Biochem. Biophys. Res. Commun. 368, 470-475.

Addo-Quaye C., Eshoo, T.W., Bartel, D.P., Axtell, M.J., 2008. Endogenous siRNA and miRNA targets identified by sequencing of the Arabidopsis degradome. Curr Biol. $18,758-762$.

Allen, E., Xie, Z., Gustafson, A.M., Carrington, J.C., 2005. MicroRNA-directed phasing during trans-acting siRNA biogenesis in plants. Cell 121, 207-221.

Ambrós, S., Hernández, C., Desvignes, J.C., Flores, R., 1998. Genomic structure of three phenotypically different isolates of peach latent mosaic viroid: implications of the existence of constraints limiting the heterogeneity of viroid quasi-species. J. Virol. 72, 7397-7406.

Axtell, M.J., 2013. Classification and comparison of small RNAs from plants. Annu. Rev. Plant Biol. 64, 137-159.

Bartel, D.P., 2009. MicroRNAs target recognition and regulatory functions. Cell 136, 215-233.

Baumberger N, Baulcombe DC., 2005. Arabidopsis ARGONAUTE1 is an RNA slicer that selectively recruits microRNAs and short interfering RNAs. Proc. Natl. Acad. Sci. USA 102, 11928-11933.

Beijerinck, M.W., 1898. Ueber ein Contagium vivum fluidum als Ursache der Fleckenkrankheit der Tabaksblatter. Verh. K. Akad. Wet. Amsterd am 65, 3-21.

Bold uc, F., Hoareau, C., St-Pierre, P., Perreault, J.P., 2010. In-depth sequencing of the siRNAs associated with peach latent mosaic viroid infection, BMC Mol. Biol. 11, 16.

Bojić, T., Beeharry, Y., Zhang da, J., Pelchat, M., 2012. Tomato RNA polymerase II interacts with the rod-like conformation of the left terminal domain of the potato spindle tuber viroid positive RNA genome. J. Gen. Virol. 93, 1591-1600.

Branch, A.D., Benenfeld, B.J., Robertson, H.D., 1988. Evidence for a single rollingcircle in the replication of potato spindle tuber viroid. Proc. Natl. Acad. Sci. USA $85,9128-9132$. 
Campos, L., Granell, P., Tárraga, S., López-Gresa, P., Conejero, V., Bellés, J.M., Rodrigo, I., Lisón, P., 2014. Salicylic acid and gentisic acid induce RNA silencingrelated genes and plant resistance to RNA pathogens. Plant Physiol. Biochem. 77, $35-43$.

Carbonell, A., Martínez de Alba, A.E., Flores, R., Gago, S., 2008. Double-stranded RNA interferes in a sequence-specific manner with infection of representative members of the two viroid families. Virology 371, 44-53.

Conejero, V., Picazo, I., Segado, P., 1979. Citrus exocortis viroid (CEV): Protein alterations in different hosts following viroid infection. Virology 97, 454-456.

Côté, F., Lévesque, D., Perreault, J.P., 2001. Natural 2',5'-phosphodiester bond s found at the ligation sites of peach latent mosaic viroid. J. Virol. 75, 19-25.

Dadami, E., Boutla, A., Vrettos, N., Tzortzakaki, S., Karakasilioti, I., Kalantidis, K., 2013. DICER-LIKE 4 but not DICER-LIKE 2 may have a positive effect on potato spindle tuber viroid accumulation in Nicotiana benthamiana. Mol. Plant 6, 232-234.

Daròs, J.A., Marcos, J.F., Hernández, C., Flores, R., 1994. Replication of avocado sunblotch viroid: Evidence for a symmetric pathway with two rolling circles and hammerhead ribozyme processing. Proc. Natl. Acad. Sci. USA 91, 12813-12817.

Daròs, J.A., Flores, R., 2002. A chloroplast protein binds a viroid RNA in vivo and facilitates its hammerhead-mediated self-cleavage. EMBO J. 21, 749-759.

Daròs, J.A., Flores, R., 2004. Arabidopsis thaliana has the enzymatic machinery for replicating representative viroid species of the family Pospiviroidae. Proc. Natl. Acad. Sci. USA 101, 6792-6797.

Davies, J.W., Kaesberg, P., Diener, T.O., 1974. Potato spindle tuber viroid. XII. An investigation of viroid RNA as a messenger for protein synthesis. Virology 61, 281286.

Delan-Forino, C., Maurel, M.C., Torchet, C., 2011. Replication of avocado sunblotch viroid in the yeast Saccharomyces cerevisiae. J. Virol. 85, 3229-3238.

Delan-Forino, C., Deforges, J., Benard, L., Sargueil, B., Maurel, M.C., Torchet, C., 2014. Structural analyses of avocado sunblotch viroid reveal differences in the folding of plus and minus RNA strands. Viruses 6, 489-506. 
De la Peña, M., Navarro, B., Flores, R., 1999. Mapping the molecular determinat of pathogenicity in a hammerhead viroid: a tetraloop within the in vivo branched RNA conformation. Proc. Natl. Acad. Sci. USA 96, 9960-9965.

den Boon, J.A., Ahlquist, P., 2010. Organelle-like membrane compartmentalization of positive-strand RNA virus replication factories. Annu. Rev. Microbiol. 64, 241-256.

Diener, T.O., 1971. Potato spindle tuber "virus": IV. A replicating, low molecular weight RNA. Virology 45, 411-428.

Diener, T.O., 1972. Potato spindle tuber viroid VIII. Correlation of infectivity with a UV-absorbing component and thermal denaturation properties of the RNA. Virology 50, 606-609.

Diener, T.O., 1989. Circular RNAs: relics of precellular evolution? Proc. Natl. Acad. Sci. USA 86, 9370-9374.

Diener T.O., Hammond R.W., Black, T., Katze, M.G., 1993. Mechanism of viroid pathogenesis: differential activation of the interferon-induced, double-stranded RNA-activated, $\mathrm{Mr} 68,000$ protein kinase by viroid strains of varying pathogenicity. Biochimie 75, 533-538.

Diener, T.O., 1996. Origin and evolution of viroids and viroid-like satellite RNAs. Virus Genes 11, 119-131.

Diener, T.O., 2001. The viroid: biological oddity or evolutionary fossil? Adv. Virus Res. 57, 137-184.

Diener, T.O., 2003. Discovering viroids: a personal perspective. Nat. Rev. Microbiol. $1,75-80$.

Diermann, N., Matousek, J., Junge, M., Riesner, D., Steger, G., 2010. Characterization of plant miRNAs and small RNAs derived from potato spindle tuber viroid (PSTVd) in infected tomato. Biol. Chem. 391, 1379-1390.

Ding, B., 2009. The biology of viroid-host interactions. Annu. Rev. Phytopathol. 47, 105-131.

Di Serio, F., Gisel, A., Navarro, B., Delgado, S., Martínez de Alba, A.E., Donvito, G., Flores, R., 2009. Deep sequencing of the small RNAs derived from two symptomatic variants of a chloroplastic viroid: implications for their genesis and for pathogenesis. PLoS One 4, e7539. 
Di Serio, F., Martínez de Alba, A.E., Navarro, B., Gisel, A., Flores, R., 2010. RNAdependent RNA polymerase 6 delays accumulation and precludes meristem invasion of a nuclear-replicating viroid. J. Virol. 84, 2477-2489.

Di Serio, F., Flores, R., Verhoeven, J.Th.J., Li, S.F., Pallás, V., Randles, J.W., Sano, T., Vidalakis, G., Owens, R.A., 2014. Current status of viroid taxonomy. Arch. Virol. 159, 3467-3478.

Dunoyer, P., Schott, G., Himber, C., Meyer, D., Takeda, A., Carrington, J.C., Voinnet, O., 2010. Small RNA duplexes function as mobile silencing signals between plant cells. Science 328, 912-916.

Eamens, A., Wang, M.B., Smith, N.A., Waterhouse, P.M., 2008. RNA silencing in plants: yesterday, today, and tomorrow. Plant Physiol. 147, 456-468.

Eamens, A.L., Smith, N.A., Dennis, E.S., Wassenegger, M., Wang, M.B. 2014. In Nicotiana species, an artificial microRNA corresponding to the virulence modulating region of potato spindle tuber viroid directs RNA silencing of a soluble inorganic pyrophosphatase gene and the development of abnormal phenotypes. Virology 450-451, 266-277.

Eiras, M., Nohales, M.A., Kitajima, E.W., Flores, R., Daròs, J.A., 2011. Ribosomal protein L5 and transcription factor IIIA from Arabidopsis thaliana bind in vitro specifically potato spindle tuber viroid RNA. Arch. Virol. 156, 529-533.

Feldstein, P.A., Hu, Y., Owens, R.A., 1998. Precisely full length, circularizable, complementary RNA: an infectiou s form of potato spindle tuber viroid. Proc. Natl. Acad. Sci. USA 95, 6560-6565.

Flores, R., Semancik, J.S., 1982. Properties of a cell-free system for synthesis of citrus exocortis viroid. Proc. Natl. Acad. Sci. USA 79, 6285-6288.

Flores, R., Daròs, J.A., Hernández, C., 2000. The Avsunviroidae family: viroids with hammerhead ribozymes. Adv. Virus Res. 55, 271-323.

Flores, R., Hernández, C., Martínez de Alba, A.E., Daròs, J.A., Di Serio, F., 2005. Viroids and viroid-host interactions. Annu. Rev. Phytopathol. 43, 117-139.

Flores, R., Gas, M.E., Molina-Serrano, D., Nohales, M.A., Carbonell, A., Gago, S., De la Peña, M., Daròs, J.A., 2009. Viroid replication: rolling-circles, enzymes and ribozymes. Viruses 1, 317-334. 
Flores, R., Ruiz-Ruiz, S., Serra, P., 2012a. Viroids and hepatitis delta virus. Semin. Liver Dis. 32, 201-210.

Flores, R., Serra, P., Minoia, S., Di Serio, F., Navarro, B., 2012b. Viroids: from genotype to phenotype just relying on RNA sequence and structural motifs. Front. Microbiol. 3, article 217.

Flores, R., Gago-Zachert, S., Serra, P., Sanjuán, R., Elena, S.F., 2014. Viroids, survivors from the RNA world? Annu. Rev. Microbiol. 68, 395-414.

Gago, S., Elena, S.F., Flores, R., Sanjuán, R., 2009. Extremely high variability of a hammerhead viroid. Science 323, 1308.

Gas, M.E., Hernández, C., Flores, R., Daròs, J.A., 2007. Processing of nuclear viroid s in vivo: an interplay between RNA conformations. PLoS Pathog. 3, 1813-1826.

Giguère, T., Adkar-Purushothama, C.R., Perreault, J.P., 2014a. Comprehensive secondary structure elucidation of four genera of the family Pospiviroidae. PLoS One 9, e98655.

Giguère, T., Adkar-Puru shothama, C.R., Bolduc, F., Perreault, J.P., 2014b. Elucidation of the structures of all members of the Avsunviroidae family. Mol. Plant Pathol. 15, 767-779.

Gómez, G., Pallás, V., 2001. Identification of an in vitro ribonucleoprotein complex between a viroid RNA and a phloem protein from cucumber plants. Mol. PlantMicrobe Interact. 14, 910-913.

Gómez, G., Pallás, V., 2012. Studies on subcellular compartmentalization of plant pathogenic non coding RNAs give new insights into the intracellular RNA-traffic mechanisms. Plant Physiol. 159, 558-564.

Gómez, G., Pallás, V., 2013. Viroids: a light in the darkness of the lncRNA-directed regulatory netwoks in plants. New Phytol. 198, 10-15.

Gozmanova, M., Denti, M. A., Minkov, I. N., Tsagris, M., Tabler, M., 2003. Characterization of the RNA motif responsible for the specific interaction of potato spindle tuber viroid RNA (PSTVd) and the tomato protein Virp1. Nucleic Acids Res. 31, 5534-5543.

Gross, H.J., Domdey, H., Lossow, C., Jank, P., Raba, M., Alberty, H., Sänger, H.L., 1978. Nucleotide sequence and secondary structure of potato spindle tuber viroid. Nature 273, 203-208. 
Haimovich, G., Medina, D.A., Causse, S.Z., Garber, M., Millán-Zambrano, G., Barkai, O., Chávez, S., Pérez-Ortín, J.E., Darzacq, X., Choder, M., 2013. Gene expression is circular: factors for mRNA degradation also foster mRNA synthesis. Cell 153, $1000-1011$.

Hall, T.C., Wepprich, R.K., Davies, J.W., Weathers, L.G., Semancik, J.S., 1974. Functional distinctions between the ribonucleic acids from citrus exocortis viroid and plant viruses: Cell-free translation and aminoacylation reactions. Virology 61, 486-492.

Hammann, C., Steger, G., 2012. Viroid-specific small RNA in plant disease. RNA Biol. 9, 809-819.

Hammond, R.W., Zhao, Y., 2000. Characterization of a tomato protein kinase gene induced by infection by potato spindle tuber viroid. Mol. Plant-Microbe Interact. $13,903-910$.

Haseloff, J., Symons, R.H., 1981. Chrysanthemum stunt viroid: Primary sequence and secondary structure. Nucleic Acids Res. 9, 2741-2752.

Haseloff, J., Mohamed, N.A., Symons, R.H., 1982. Viroid RNAs of the cadang-cadang disease of coconuts. Nature 229, 316-321.

Hernández, C., and Flores, R. 1992. Plus and minus RNAs of peach latent mosaic viroid self-cleave in vitro via hammerhead structures. Proc. Natl. Acad. Sci. USA $89,3711-3715$.

Hui-Bon-Hoa, G., Kaddour, H., Vergne, J., Kruglik, S.G., Maurel, M.C., 2014. Raman characterization of avocado sunblotch viroid and its response to external perturbations and self-cleavage. BMC Biophys. 7, 2.

Hutchins, C.J., Keese, P., Visvader, J.E., Rathjen, P.D., McInnes, J.L., Symons, R.H., 1985. Comparison of multimeric plus and minus forms of viroids and virusoids. Plant Mol. Biol. 4, 293-304.

Hutchins, C., Rathjen, P.D., Forster, A.C., Symons, R.H., 1986. Self-cleavage of plus and minus RNA transcripts of avocado sunblotch viroid. Nucleic Acids Res. 14, $3627-3640$.

Itaya, A., Zhong, X., Bundschuh, R., Qi, Y., Wang, Y., Takeda, R., Harris, A.R., Molina, C., Nelson, R.S., Ding, B., 2007. A structured viroid RNA is substrate for 
Dicer-like cleavage to produce biologically active small RNAs but is resistant to RISC-mediated degradation. J. Virol. 81, 2980-2994.

Ito, T., Suzaki, K., Nakano, M., Sato, A., 2013. Characterization of a new apscaviroid from American persimmon. Arch. Virol. 158, 2629-2631.

Iwakawa, H.O., Tomari, Y., 2013. Molecular insights into microRNA-mediated translational repression in plants. Mol Cell 52, 591-601.

Kasai, A., Sano, T., Harada, T., 2013. Scion on a stock producing siRNAs of potato spindle tuber viroid (PSTVd) attenuates accumulation of the viroid. PloS One 8, e57736.

Kovalskaya, N., Hammond, R.W., 2014. Molecular biology of viroid-host interactions and disease control strategies. Plant Sci. 228, 48-60.

Liu, Q., Wang, F., Axtell, M.J., 2014. Analysis of complementarity requirements for plant microRNA targeting using a Nicotiana benthamiana quantitative transient assay. Plant Cell 26, 741-753.

Llave, C., 2010. Virus-derived small interfering RNAs at the core of plant-virus interactions. Trends Plant Sci. 15, 701-707.

Malfitano, M., Di Serio, F., Covelli, L., Ragozzino, A., Hernández, C., Flores, R., 2003. Peach latent mosaic viroid variants inducing peach calico (extreme chlorosis) contain a characteristic insertion that is responsible for this symptomatology. Virology 313, 492-501.

Mallory, A.C., Reinhart, B.J., Jones-Rhoades, M.W., Tang, G., Zamore, P.D., Barton, M.K., Bartel, D.P., 2004. MicroRNA control of PHABULOSA in leaf development: importance of pairing to the microRNA 5' region. EMBO J. 23, 3356-3364.

Mallory, A.C., Vaucheret, H., 2009. ARGONAUTE 1 homeostasis invokes the coordinate action of the microRNA and siRNA pathways. EMBO Rep. 10, 521-526.

Mallory, A., Vaucheret, H., 2010. Form, function, and regulation of ARGONAUTE proteins. Plant Cell 22, 3879-3889.

Martínez de Alba, A.E., Sägesser, R., Tabler, M., Tsagris, M., 2003. A bromodomaincontaining protein from tomato specifically binds potato spindle tuber viroid RNA in vitro and in vivo. J. Virol. 77, 9685-9694. 
Martínez, G., Castellano, M., Tortosa, M., Pallás, V., Gómez, G. 2014. A pathogenic non-coding RNA induces changes in dynamic DNA methylation of ribosomal RNA genes in host plants. Nucleic Acids Res. 42, 1553-1562.

Matousek, J., Kozlová, P., Orctová, L., Schmitz, A., Pesina, K., Bannach, O., Diermann, N., Steger, G., and Riesner, D., 2007. Accumulation of viroid-specific small RNAs and increase in nucleolytic activities linked to viroid-caused pathogenesis. Biol. Chem. 388, 1-13.

Matousek, J., Orctová, L., Skopek, J., Pesina, K., Steger, G., 2008. Elimination of hop latent viroid upon developmental activation of pollen nuclease. Biol. Chem. 389, 905-918.

McInnes, J.L., Symons, R.H., 1991. Comparative structure of viroids and their rapid detection using radioactive and nonradioactive nucleic acid probes, in: Maramorosch, K., (Ed.), Viroids and Satellites: Molecular Parasites at the Frontier of Life. CRC Press, Boca Raton, pp. 21-58.

Mi, S., Cai, T., Hu, Y., Chen, Y., Hodges, E., Ni, F., Wu, L., Li, S., Zhou, H., Long, C., Chen, S., Hannon, G.J., Qi, Y., 2008. Sorting of small RNAs into Arabidopsis argonaute complexes is directed by the 5 ' terminal nucleotide. Cell 133, 116-127.

Minoia, S., Carbonell, A., Di Serio, F., Gisel, A., Carrington, J.C., Navarro, B., Flores, R., 2014. Specific ARGONAUTES bind selectively small RNAs derived from potato spindle tuber viroid and attenuate viroid accumulation in vivo. J. Virol. 88, 11933-11945.

Minoia, S., Navarro, B., Degado, S., Di Serio, F., Flores, R., 2015. Viroid RNA turnover: characterization of the subgenomic RNAs of potato spindle tuber viroid accumulating in infected tissues provides insights into decay pathways operating in vivo. Nucleic Acids Res. doi: 10.1093/ nar/ gkv034.

Moissiard, G., Voinnet, O., 2006. RNA silencing of host transcripts by cauliflower mosaic virus requires coordinated action of the four Arabidopsis Dicer-like proteins. Proc. Natl Acad. Sci. USA 103, 19593-19598.

Molnar, A., Melnyk, C.W., Bassett, A., Hardcastle, T.J., Dunn, R., Baulcombe, D.C., 2010. Small silencing RNAs in plants are mobile and direct epigenetic modification in recipient cells. Science 328, 872-875. 
Molnar, A., Csorba, T., Lakatos, L., Varallyay, E., Lacomme, C., Burgyan, J., 2005. Plant virus-derived small interfering RNAs originate predominantly from highly structured single-stranded viral RNAs. J. Virol. 79, 7812-7818.

Montgomery, T.A., How ell, M.D., Cuperu s, J.T., Li, D., Hansen, J.E., Alexander, A.L., Chapman, E.J., Fahlgren, N., Allen, E., Carrington, J.C., 2008. Specificity of ARGONAUTE7-miR390 interaction and dual functionality in TAS3 trans-acting siRN A formation. Cell 133, 128-141.

Morel, J.B., Godon, C., Mourrain, P., Béclin, C., Boutet, S., Feuerbach, F., Proux, F., Vaucheret, H., 2002. Fertile hypomorphic ARGONAUTE (ago1) mu tants impaired in post-transcriptional gene silencing and virus resistance. Plant Cell 14, 629-639.

Mühlbach, H.P., Sänger, H.L., 1979. Viroid replication is inhibited by $\alpha$-amanitin. Nature 278, 185-188.

Navarro, B., Flores, R., 1997. Chrysanthemum chlorotic mottle viroid: unusual structural properties of a subgroup of viroids with hammerhead ribozymes. Proc. Natl. Acad. Sci. USA 94, 11262-11267.

Navarro, J.A., Daròs, J.A., Flores, R., 1999. Complexes containing both polarity strands of avocado sunblotch viroid: identification in chloroplasts and characterization. Virology 253, 77-85.

Navarro, J.A., Vera, A., Flores, R., 2000. A chloroplastic RNA polymerase resistant to tagetitoxin is involved in replication of avocado sunblotch viroid. Virology 268, $218-225$

Navarro, B., Gisel, A., Rodio, M.E., Delgad o, S., Flores, R., Di Serio, F., 2012a. Viroids: how to infect a host and cause disease without encoding proteins. Biochimie 94, $1474-1480$

Navarro, B., Gisel, A., Rodio, M.E., Delgado, S., Flores, R., Di Serio, F., 2012b. Small RNAs containing the pathogenic determinant of a chloroplast-replicating viroid guide the degradation of a host mRNA as predicted by RNA silencing. Plant J. 70, 991-1003.

Nohales, M.A., Flores, R., Daròs, J.A., 2012a. A viroid RNA redirects host DNA ligase 1 to act as an RNA ligase. Proc. Natl. Acad. Sci. USA 109, 13805-13810. 
Nohales, M.A., Molina-Serrano, D., Flores, R., Daròs, J.A., 2012b. Involvement of the chloroplastic isoform of tRNA ligase in the replication of the viroids belonging to the family Avsunviroidae. J. Virol. 86, 8269-8276.

Omarov, R.T., Cioperlik, J.J., Sholthof, H.B., 2007. RNAi-associated ssRNA-specific ribonucleases in tombusvirus P19 mutant-infected plants and evidence for a discrete siRNA-containing effector complex. Proc. Natl. Acad. Sci. USA 104, 17141719.

Owens, R.A., Blackburn, M., Ding, B., 2001. Possible involvement of the phloem lectin in long-distance viroid movement. Mol. Plant-Microbe Interact. 14, 905-909.

Palukaitis, P. 2014. What has been happening with viroids? Virus Genes 49, 175-184.

Pantaleo, V., Szittya, G., Burgyán, J., 2007. Molecular bases of viral RNA targeting by viral small interfering RNA-programmed RISC. J. Virol. 81, 3797-3806.

Papaefthimiou, I., Hamilton, A.J., Denti, M.A., Baulcombe, D.C., Tsagris, M., Tabler, M., 2001. Replicating potato spindle tuber viroid RNA is accompanied by short RNA fragments that are characteristic of post-transcriptional gene silencing, Nucleic Acids Res. 29, 2395-2400.

Pasek, M.A., Harnmeijer, J.P., Buick. R., Gull, M., Atlas, Z. 2013. Evidence for reactive reduced phosphorus species in the early Archean ocean. Proc. Natl. Acad. Sci. USA 110: 10089-10094.

Prody, G.A., Bakos, J.T., Buzayan, J.M., Schneider, I.R., Bruening, G., 1986. Autolytic processing of dimeric plant virus satellite RNA. Science 231, 1577-1580.

Qi, Y., Ding, B., 2003. Differential subnuclear localization of RNA strand s of opposite polarity derived from an autonomously replicating viroid. Plant Cell 15, 25662577.

Qi, Y., Pélissier, T., Itaya, A., Hunt, E., Wassenegger, M., Ding, B., 2004. Direct role of a viroid RNA motif in mediating directional RNA trafficking across a specific cellular boundary. Plant Cell 16, 1741-1752.

Qi, Y., Denli, A.M., Hannon, G.J., 2005. Biochemical specialization within Arabidopsis RNA silencing pathways. Mol. Cell 19, 421-428.

Riesner, D., Henco, K., Rokohl, U., Klotz, G., Kleinschmidt, A.K., Domdey, H., Jank, P., Gross, H.J., Sänger, H.L., 1979. Structure and structure formation of viroids. J. Mol. Biol. 133, 85-115. 
Rizzetto, M., Hoyer, B., Canese, M.G., Shih, J.W., Purcell, R.H., Gerin, J.L., 1980. $\partial$ agent: Association of $\partial$ antigen with hepatitis B surface antigen and RNA in serum of $\partial$-infected chimpanzees. Proc. Natl. Acad. Sci. USA 77, 6124-6128.

Rodio, M.E., Delgado, S., Flores, R., Di Serio, F., 2006. Variants of peach latent mosaic viroid inducing peach calico: Uneven distribution in infected plants and requirements of the insertion containing the pathogenicity determinant. J. Gen. Virol. 87, 231-240.

Rodio, M.E., Delgado, S., De Stradis, A.E., Gómez, M.D., Flores, R., Di Serio, F., 2007. A viroid RNA with a specific structural motif inhibits chloroplast development. Plant Cell 19, 3610-3626.

Ruiz-Ruiz, S., Soler, N., Sánchez-Navarro, J., Fagoaga, C., López, C., Navarro, L., Moreno, P., Peña, L., Flores, R., 2013. Citrus tristeza virus p23: Determinants for nucleolar localization and their influence on suppression of RNA silencing and pathogenesis. Mol. Plant-Microbe Interact. 26, 306-318.

Sänger, H.L., Klotz, G., Riesner, D., Gross, H.J., Kleinschmidt A.K., 1976. Viroids are single-stranded covalently-closed circular RNA molecules existing as highly basepaired rod-like structures, Proc. Natl. Acad. Sci. USA 73, 3852-3856.

Sano, T., Barba, M., Li, S.F., Hadidi, A., 2010. Viroid s and RNA silencing. Mechanism, role in viroid pathogenicity and development of viroid -resistant plants. GM Crops $1,80-86$.

Schiebel, W., Pélissier, T., Riedel, L., Thalmeir, S., Schiebel, R., Kempe, D., Lottspeich, F., Sänger, H.L., Wassenegger, M., 1998. Isolation of an RNA-directed RNA polymerase-specific cDNA clone from tomato. Plant Cell 10, 2087-2101.

Schindler, I.M., Mühlbach, H.P., 1992. Involvement of nuclear DNA-dependent RNA polymerases in potato spindle tuber viroid replication: A reevaluation. Plant Sci. 84, 221-229.

Scholthof, K.B., 2014. Making a virus visible: Francis O. Holmes and a biological assay for tobacco mosaic virus. J. Hist. Biol. 47, 107-145.

Schuck, J., Gursinsky, T., Pantaleo, V., Burgyan, J., Behrens, S.E., 2013. AGO/ RISCmediated antiviral RNA silencing in a plant in vitro system. Nucleic Acids Res. 41, 5090-5103. 
Schwind, N., Zwiebel, M., Itaya, A., Ding, B., Wang, M.B., Krczal, G., Wassenegger, M., 2009. RNAi-mediated resistance to potato spindle tuber viroid in transgenic tomato expressing a viroid hairpin RNA construct. Mol. Plant Pathol. 10, 459-469.

Semancik, J.S., Conejero, V., Gerhart, J., 1977. Citrus exocortis viroid: Survey of protein synthesis in Xenopus laevis oocytes following addition of viroid RNA. Virology 80, 218-221.

Semancik, J.S., Szychow ski, J.A., 1994. Avocado sunblotch disease: a persistent viroid infection in which variants are associated with differential symptoms. J. Gen. Virol. 75, 1543-1549.

Semancik, J.S., Szychowski, J.A., Rakow ski, A.G., Symons, R.H., 1994. A stable 463 nucleotide variant of citrus exocortis viroid produced by terminal repeats. J. Gen. Virol. 75, 727-732.

Serra, P., Bani-Hashemian, S.M., Fagoaga, C., Romero, J., Ruiz-Ruiz, S., Gorris, M.T., Bertolini, E., Duran-Vila, N., 2014. Virus-viroid interactions: citrus tristeza virus enhances the accumulation of citrus dwarfing viroid in Mexican lime via the viralencoded silencing suppressors. J. Virol. 88, 1394-1397.

Shimura, H., Pantaleo, V., Ishihara, T., Myojo, N., Inaba J.-I., Sueda, K., Burgyán, J., Masuta, C., 2011. A viral satellite RNA induces yellow symptoms on tobacco by targeting a gene involved in chlorophyll biosynthesis using the RNA silencing machinery, PLoS Pathog. 7, e1002021.

Singh, R.P., 1971. A local lesion host for potato spindle tuber virus. Phytopathology 61, 1034-1035.

Smith, N.A., Eamens, A.L., Wang M.-B., 2011. Viral small interfering RNAs target host genes to mediate disease symptoms in plants. PLoS Pathog. 7, e1002022.

Solovyev, A.G., Makarova, S.S., Remizowa, M.V., Lim, H.S., Hammond, J., Owens, R.A., Kopertekh, L., Schiemann, J., Morozov, S.Y., 2013. Possible role of the Nt-4/ 1 protein in macromolecular transport in vascular tissue. Plant Signal Behav. 8, e25784.

Spiesmacher, E., Mühlbach, H.P., Schnölzer, M., Haas, B., Sänger, H.L., 1983. Oligomeric forms of potato spindle tuber viroid (PSTV) and of its complementary RNA are present in nuclei isolated from viroid-infected potato cells. Biosci. Rep. 3, 767-774 
Symons, R.H., 1981. Avocado sunblotch viroid: primary sequence and proposed structure, Nucleic Acids Res. 9, 6527-6537.

Takeda, A., Iwasaki, S., Watanabe, T., Utsumi, M., Watanabe, Y., 2008. The mechanism selecting the guide strand from small RNA duplexes is different among Argonaute proteins. Plant Cell Physiol. 49, 493-500.

Taked a, R., Petrov, A.I., Leontis, N.B., Ding, B., 2011. A three-dimensional RNA motif in potato spindle tuber viroid mediates trafficking from palisade mesophyll to spongy mesophyll in Nicotiana benthamiana. Plant Cell 23, 258-272.

Tsagris, E.M., Martínez de Alba, A.E., Gozmanova, M., Kalantidis, K., 2008. Viroids. Cell Microbiol. 10, 2168-2179.

Várallyay, E., Valoczi, A., Agyi, A., Burgyán, J., Havelda, Z., 2010. Plant virusmediated induction of miR168 is associated with repression of ARGONAUTE1 accumulation. EMBO J. 29, 3507-3519.

Verhoeven, J.T., Meekes, E.T., Roenhorst, J.W., Flores, R., Serra, P., 2013. Dahlia latent viroid: a recombinant new species of the family Pospiviroidae posing intriguing questions about its origin and classification. J. Gen. Virol. 94, 711-719.

Vogt, U., Pelissier, T., Putz, A., Razvi, F., Fischer, R., Wassenegger, M., 2004. Viroid induced RNA silencing of GFP-viroid fusion transgenes does not induce extensive spreading of methylation or transitive silencing. Plant J. 1, 107-118.

Wang, M.B., Bian, X.Y., Wu, L.M., Liu, L.X., Smith, N.A., Isenegger, D., Wu, R.M., Masuta, C., Vance, V.B., Watson, J.M., Rezaian, A., Dennis, E.S., Waterhou se, P.M., 2004. On the role of RNA silencing in the pathogenicity and evolution of viroids and viral satellites, Proc. Natl. Acad. Sci. USA 101, 3275-3280.

Wang, Y., Shibuya, M., Taneda, A., Kurauchi, T., Senda, M., Owens, R.A., Sano, T., 2011. Accumulation of potato spindle tuber viroid-specific small RNAs is accompanied by specific changes in gene expression in two tomato cultivars. Virology 413, 72-83.

Wang, M.B., Masuta, C., Smith, N.A., Shimura, H., 2012. RNA silencing and plant viral diseases. Mol. Plant-Microbe Interact. 25, 1275-1285.

Wang, L.P., He, Y., Kang, Y.P., Hong, N., Farooq, A.B.U., Wang, G.P., Xu, W.X., 2013. Virulence determination and molecular features of peach latent mosaic viroid 
isolates derived from phenotypically different peach leaves: A nucleotide polymorphism in L11 contributes to symptom alteration. Virus Res. 177, 171-178.

Wang, Y., Wu, J., Ding, B., 2014. A deeply conserved transcription factor regulates the replication of potato spindle tuber viroid RNA genome. XVIth Internatl. Congress of Virology. Montreal.

Warrilow, D., Symons, R.H., 1999. Citrus exocortis viroid RNA is associated with the largest subunit of RNA polymerase II in tomato in vivo. Arch. Virol. 144, 23672375 .

Wassenegger, M., Heimes, S., Sänger, H.L., 1994a. An infectious viroid RNA replicon evolved from an in vitro-generated non-infectious viroid deletion mutant via a complementary deletion in vivo. EMBO J. 13, 6172-6177.

Wassenegger, M., Heimes, S., Riedel, L., Sänger, H.L., 1994b. RNA-directed de novo methylation of genomic sequences in plants. Cell 76, 567-576.

Wassenegger, M., Krczal, G., 2006. Nomenclature and functions of RNA-directed RNA polymerases. Trends Plant Sci. 11, 142-151.

Woo, Y.M., Itaya, A., Owens, R.A., Tang, L., Hammond, R.W., Chou, H.C., Lai, M.M.C., Ding, B., 1999 Characterization of nuclear import of potato spindle tuber viroid RNA in permeabilized protoplasts. Plant J. 17, 627-635.

Wu, Q., Wang, Y., Cao, M., Pantaleo, V., Burgyan, J., Li, W.X., Ding, S.W., 2012. Homology-independent discovery of replicating pathogenic circular RNAs by deep sequencing and a new computational algorithm. Proc. Natl. Acad. Sci. USA $109,3938-3943$.

Zhang, Z., Qi, S., Tang, N., Zhang, X., Chen, S., Zhu, P., Ma, L., Cheng, J., Xu, Y., Lu, M., Huang, H., Ding, S.W., Li, S., Wu, Q., 2014. Discovery of replicating circular RNAs by RNA-seq and computational algorithms. PLoS Pathog. 10, e1004553.

Zhao, Y., Owens, R.A., Hammond, R.W., 2001. Use of a vector based on potato virus $\mathrm{X}$ in a whole plant assay to demonstrate nuclear targeting of potato spindle tuber viroid. J. Gen. Virol. 82, 1491-1497.

Zhong, X., Tao, X., Stombaugh, J., Leontis, N., Ding, B., 2007. Tertiary structure and function of an RNA motif required for plant vascular entry to initiate systemic trafficking. EMBO J. 26, 3836-3846. 
Zhong, X., Archual, A.J., Amin, A.A., Ding, B., 2008. A genomic map of viroid RNA motifs critical for replication and systemic trafficking. Plant Cell 20, 35-47. 


\section{Legends to Figures}

Figure 1. Descending scale of genomic size. Approximate values are expressed in DNA base pairs, except for the phage MS2 and viroid genomes that are expressed in RNA bases. The genome size of Triticum aestivum (wheat) is an estimate.

Figure 2. Healthy peach leaf (left), and partial (center) and complete (right) leaf albinism, termed peach calico, incited by variants of PLMVd containing a specific 1214 nucleotide hairpin insertion. Reproduced with modifications from Navarro et al. (2012) Plant Journal 70, 991-1003.

Figure 3. Specific cleavage of peach cHSP90 mRNA mediated by PC-sRNA8a. Upper part, cHSP90 mRNA:PC-sRNA8a duplex (in bold), with the sequence of PC-sRNA8a corresponding to the PC-associated insertion underlined. Arrows mark the cleavage sites predicted and validated by RLM-RACE from five independent clones (fractions indicate number of clones producing the same results). Reproduced with modifications from Navarro et al. (2012) Plant Journal 70, 991-1003.

Figure 4. Criteria supporting the notion that the 21-nt PC-sRNA8a and b incite peach calico (albinism) via PTGS-mediated cleavage of the mRNA coding for the cHSP90.

Figure 5. Northern-blot hybridizations of peach RNA preparations with riboprobes for detecting (+) (left) and (-) (right) PLMVd strands following fractionation by denaturing PAGE. The positions of the monomeric circular (mc) and linear (ml) PLMVd RNAs are indicated at left (panel A). The progeny of the PLMVd variant inducing PC (PC-C40) accumulates at a significantly higher level in the albino (A) than in the green $(G)$ sectors of the same leaf (panel B). Loading was equalized with respect to the nucleus-encoded rRNAs. Reproduced with modifications from Rodio et al. (2007) Plant Cell 19, 3610-3626. 
Triticum aestivum -16.000 .000 .000$

2.900 .000 .000 Homo sapiens
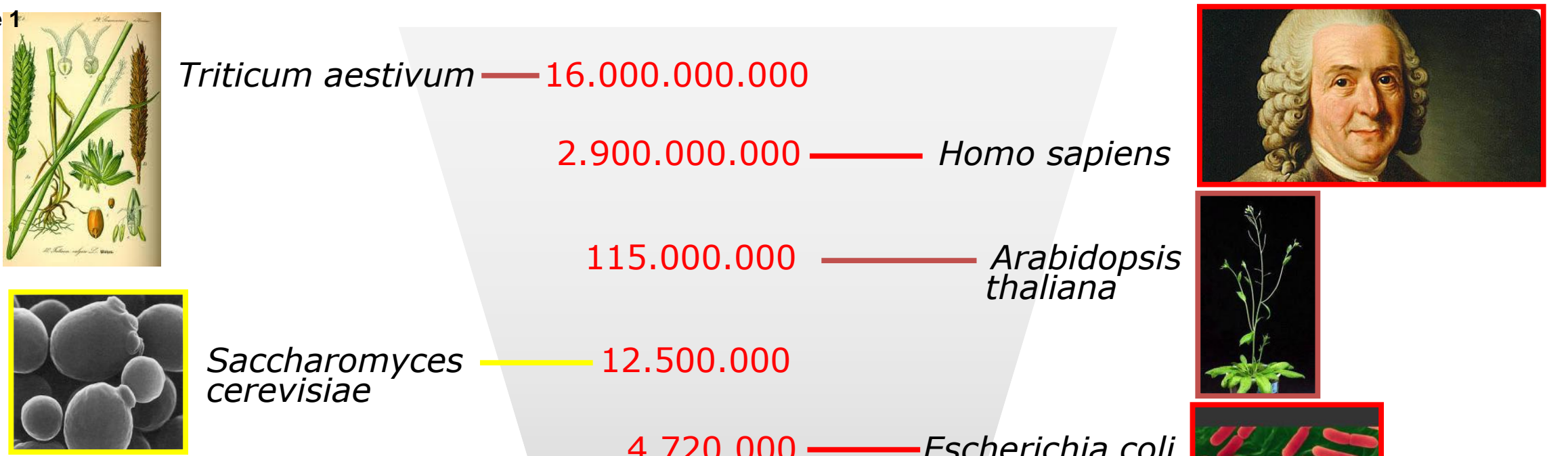

115.000 .000

Arabidopsis thaliana

\section{Saccharomyces cerevisiae}

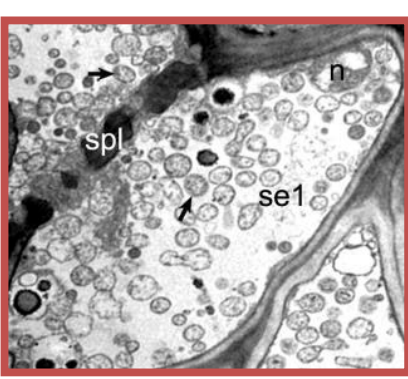

Phytoplasma

12.500 .000
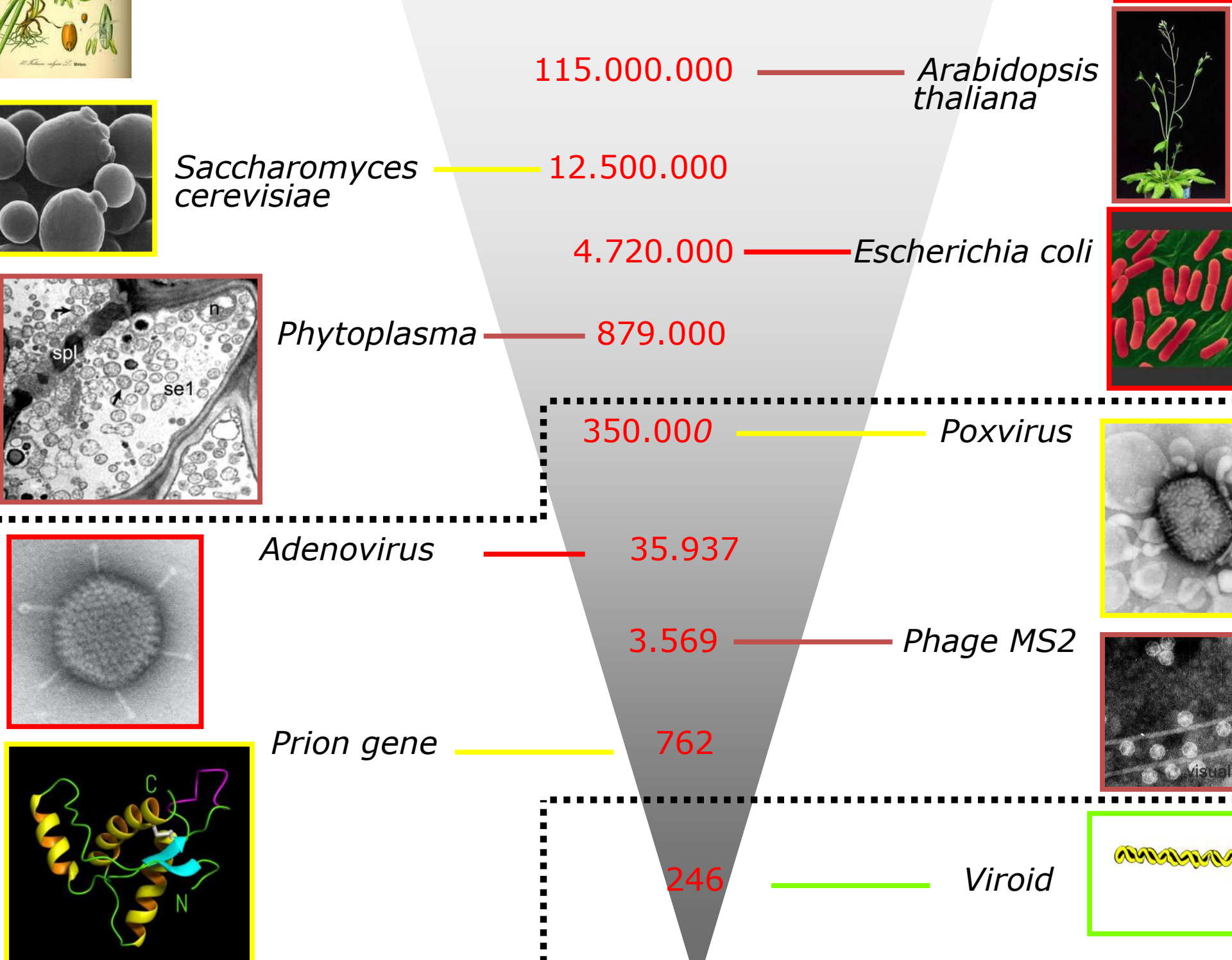

Prion gene
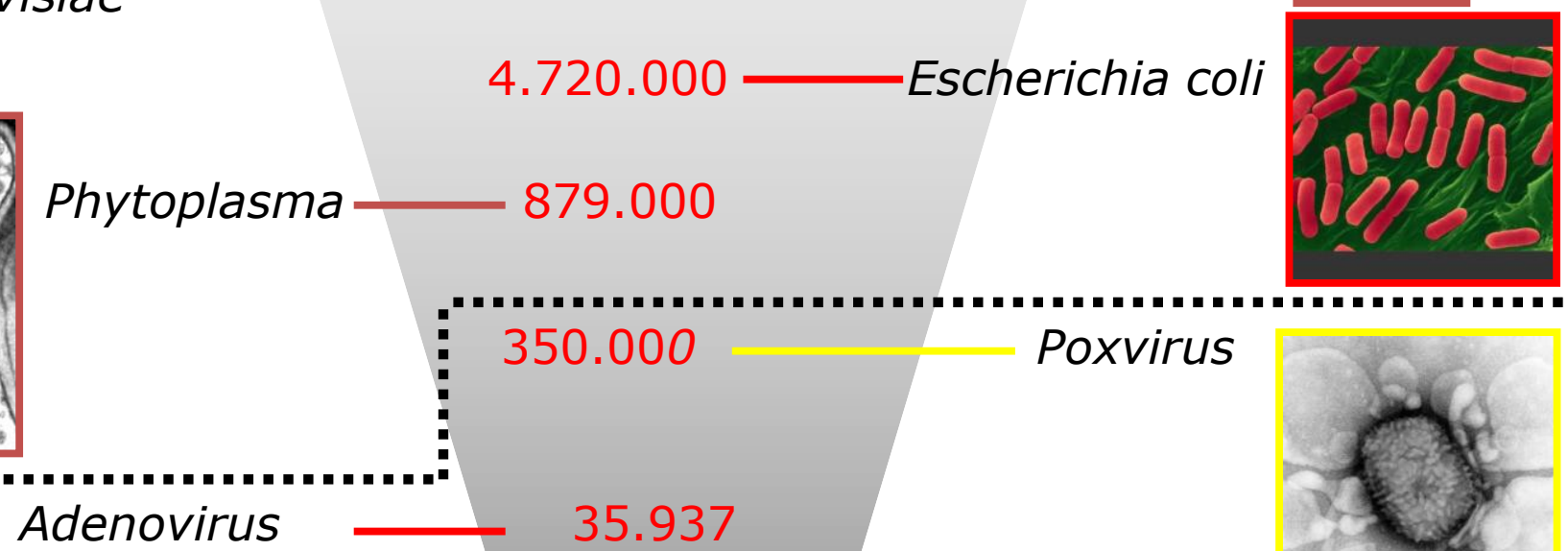

350.000

Poxvirus

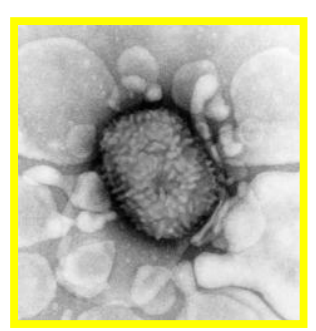

Phage MS2

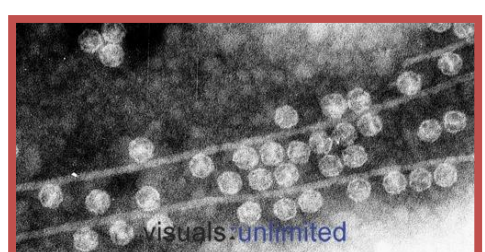

Viroid

asmanaranano

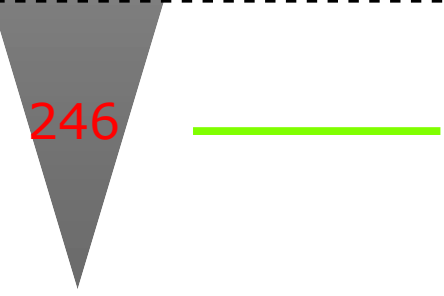



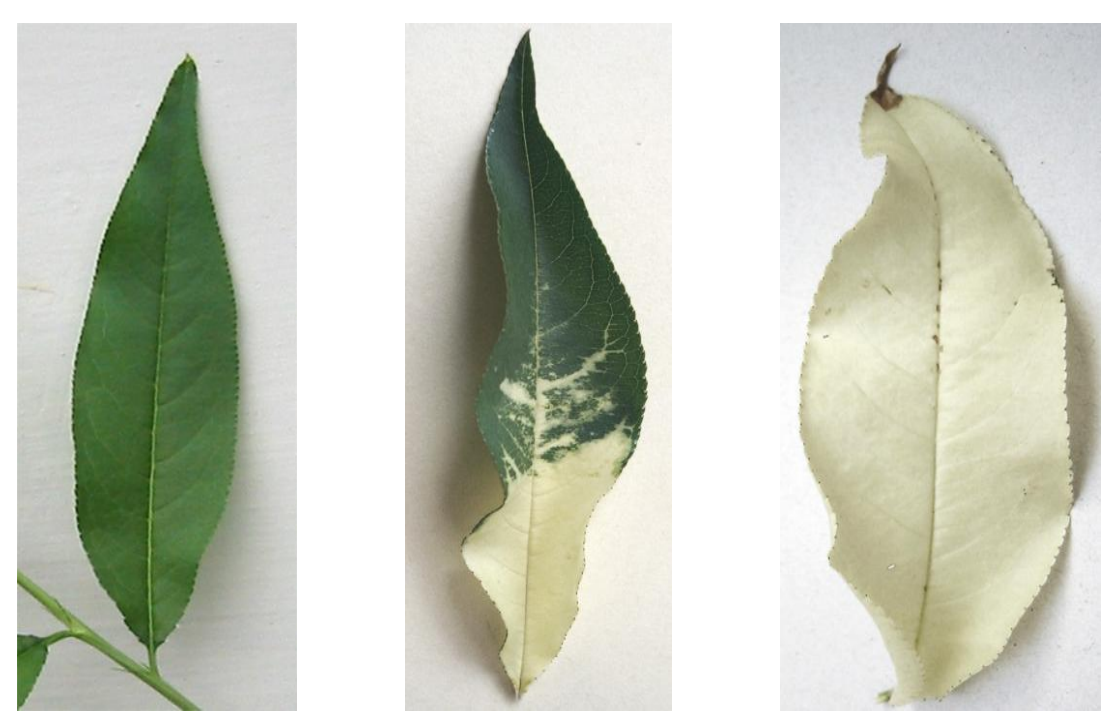

Figure 2 
Figure 3

cHSP90 mRNA $55^{\prime}-\ldots$ AgCCUGAGAAGUGCUUUUGUUCCUCAAAAUGGGCUCAGGAAGG . . - 3'

PC-sRNA8a

|| | |||||||||||||||||

$3^{\prime}$-UUCUCGAAAACAAGGAGUUUU-5'

336

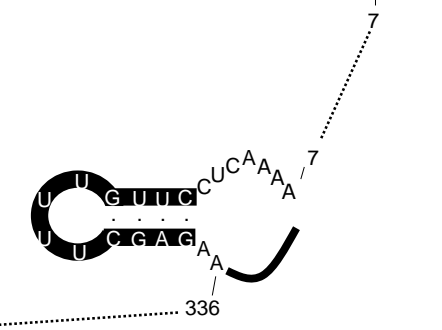

Figure 3

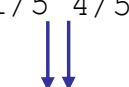


PC-sRNA8a and b (21 nt) incite peach calico (PC) via PTGS: supporting criteria

1. Contain the pathogenic determinant strictly associated with PC (albinism)

2. Exist only in albino leaf sectors but not in the green surrounding tissue

3. Fulfill thermodynamic considerations for being functional siRNAs

4. Hybridize with cHSP90 mRNA according to accepted predicting rules

5. Cleavage of cHSP90 mRNA coincides with the middle position of the sRNAs

6. Have a 5' -terminal U: they are most likely loaded by AGO1

7. Mutants of the gene coding for cHSP90 result in albino phenotypes

\section{Figure 4}


A

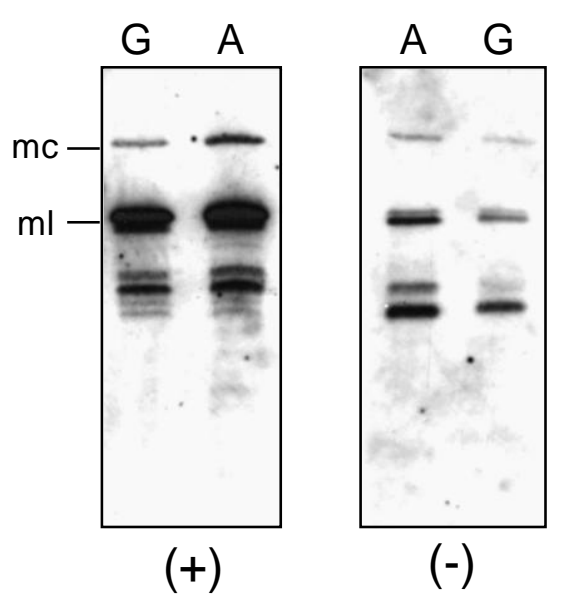

B

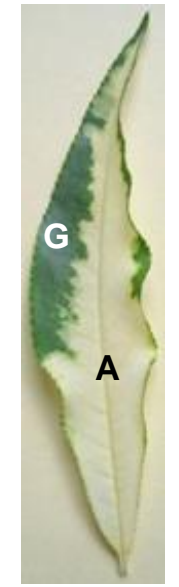

Figure 5 